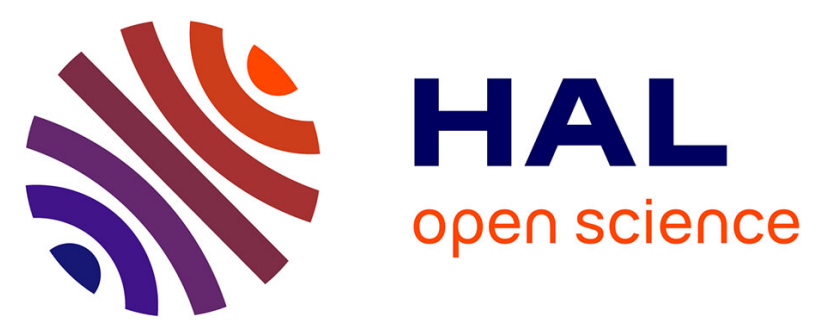

\title{
MICROANALYSIS TECHNIQUE USING ELECTRON ENERGY LOSS SPECTROSCOPY IN HIGH VOLTAGE ELECTRON MICROSCOPY
}

\author{
Jean Sévely, Yolande Kihn, G. Zanchi, B. Jouffrey
}

\section{- To cite this version:}

Jean Sévely, Yolande Kihn, G. Zanchi, B. Jouffrey. MICROANALYSIS TECHNIQUE USING ELECTRON ENERGY LOSS SPECTROSCOPY IN HIGH VOLTAGE ELECTRON MICROSCOPY. Journal de Physique Colloques, 1984, 45 (C2), pp.C2-441-C2-444. 10.1051/jphyscol:19842100 . jpa00223767

\section{HAL Id: jpa-00223767 https://hal.science/jpa-00223767}

Submitted on 1 Jan 1984

HAL is a multi-disciplinary open access archive for the deposit and dissemination of scientific research documents, whether they are published or not. The documents may come from teaching and research institutions in France or abroad, or from public or private research centers.
L'archive ouverte pluridisciplinaire HAL, est destinée au dépôt et à la diffusion de documents scientifiques de niveau recherche, publiés ou non, émanant des établissements d'enseignement et de recherche français ou étrangers, des laboratoires publics ou privés. 


\title{
MICROANALYSIS TECHNIQUE USING ELECTRON ENERGY LOSS SPECTROSCOPY IN HIGH VOLTAGE ELECTRON MICROSCOPY
}

\author{
J. Sevely, Y. Kihn, G. Zanchi and B. Jouffrey \\ Laboratoire d'optique Electronique du C.N.R.S.*, 29 me Jeanne Mamig, \\ 31055 Toulouse Cedex, France
}

\begin{abstract}
Résumé : En vue de l'utilisation de la spectroscopie de pertes d'énergie d'électrons ä très haute tension, pour le développement de la microanalyse, on étudie la variation du contraste des distributions caractéristiques d'ionisation du niveau $K$ du carbone en fonction de 1 'énergie des électrons primaires (entre 0,3 et $1 \mathrm{MeV}$ ). Cette étude permet de conclure à un avantage des hautes tensions dans ce domaine.
\end{abstract}

Abstract : With the purpose of using EELS for the development of microanalysis, the variation of the jump-ratio at the carbon K-edge is studied as a function of the primary electron incident energy $(0.3-1 \mathrm{MeV})$. This study shows an interest in using high accelerating voltage in that field.

\section{INTRODUCTION}

The adaptation of electron energy loss spectrometers to high voltage electron microscopes (1), (2) allows to achieve energy loss spectra, the energy resolution of which is comparable with the one obtained on a one hundred kilovolt electron microscope equipped with a thermoionic electron source. These spectra show the various kinds of interactions of the incident electrons with the sample (1). The purpose of this paper is to study the influence of the accelerating voltage upon the sensibility of the chemical microanalysis technique using the characteristic distributions associated with the inner shell excitation of the specimen atoms. The inferences we draw from this study are illustrated in the field of biology and metallurgy, in some contributions of these proceedings.

\section{THE EXPERIMENTAL DEVICE}

The experiments have been performed on a $300-1000 \mathrm{kV}$ conventional transmission electron microscope equipped with an omega filtering device (2). The electron counting system consists of a charged particle detector connected to a pulse processing system. An amplitude selector allows to separate the pulses due to $X$-rays and to remove the $X$-ray parasite signal from the spectra (3).

\section{CONTRAST OF CHARACTERISTIC DISTRIBUTIONS}

The relative importance of the characteristic signal can be evaluated by comparing it to the background intensity. We have chosen to represent the characteristic signal contrast $C$ by the jump ratio (4), $C=I_{M} / I_{m}$, where $I_{M}$ is the maximum intensity of the characteristic distribution and $I_{m}$ is the background intensity just before the ionisation edge, (Fig. 1)

The experimental results have been compared with the theoretical ones got from computed spectra. A general procedure has been developed for the computation of the spectra which are described by considering three different kinds of inelastic scattering processes. The Poisson's statistics are applicable to the description of the scattering in the specimen.

\footnotetext{
‡associê à l'Université Paul Sabatier
} 


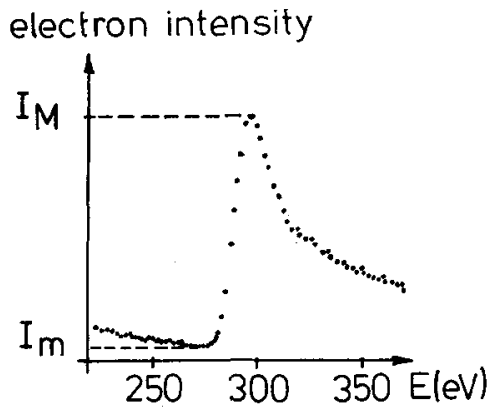

Fig. 1 : Definition of the contrast of the characteristic distribution corresponding to a $\mathrm{K}-$ ionisation edge.

The Fourier transform $\overline{\mathscr{F}}\left(\omega, \theta_{d}\right)$ of the intensity $\mathscr{\mathscr { F }}\left(\mathrm{E}, \theta_{\mathrm{d}}\right)$ transmitted by the sample through the objective lens aperture $\left(\theta_{d}\right)$ can be written :

$$
\mathscr{J}\left(\omega, \theta_{D}\right)=\hat{G}_{s}(\omega)\left[1+\frac{t}{\lambda_{1}} F\left(\theta_{d}\right) \frac{\lambda_{1}}{\lambda_{K}} \hat{g}_{K}(\omega)\right] \exp \left(\frac{t}{\lambda_{1}} F\left(\theta_{d}\right)\left[\hat{g}_{1}(\omega)+\frac{\lambda_{1}}{\lambda_{2}} \hat{g}_{2}(\omega)\right]\right)
$$

where, $\lambda_{1}$ is the mean free path for the main inelastic scattering process (buik plasmon excitation), $\lambda_{2}$ the mean free path for a secondary inelastic process of minor importance, which also contributes to the background formation and $\lambda_{k}$ the mean free path for the ionisation process. $\hat{g}_{1}(\omega), \hat{g}_{2}(\omega)$ and $\hat{g}_{k}(\omega)$ are the Fourier transforms of the energy loss functions $g_{1}(E), g_{2}(E), g_{K}(E)$ associated respectively with the inelastic processes defined previousfy (5). These normalized functions represent the probability for an electron to undergo a given energy loss $E$ after an interaction of the corresponding kind. $F\left(\Theta_{d}\right)$ is a function of the angle $\theta_{d}$ defined by the objective lens diaphragm. It reports the angular scattering in the specimen. $\hat{G}_{S}(\omega)$ is the Fourier transform of the apparatus transfer function $G_{S}(E)$; the later takes into account the energy fluctuations of the incident beam and the selecting slit effects of the dispersive system.

The first two inelastic processes originate the background intensity which is interpreted in term of plural electron scattering. The third inelastic event is Tiable for the characteristic distribution of the spectra.

If. $\mathscr{C}\left(E, \theta_{d}\right)$ is the background intensity computed from the reverse Fourier transform of the function

$$
\hat{\mathscr{F}}_{\mathrm{c}}(\omega)=\hat{G}_{\mathrm{s}}(\omega) \exp \left(\frac{t}{\lambda_{1}} \mathrm{~F}\left(\Theta_{\mathrm{d}}\right)\left[\hat{g}_{1}(\omega)+\frac{\lambda_{1}}{\lambda_{2}} \hat{g}_{2}(\omega)\right]\right)
$$

then $\mathscr{F}\left(\mathrm{E}, \theta_{\mathrm{d}}\right)$ can be written :

$$
\mathscr{F}\left(E, \theta_{d}\right) \equiv \mathscr{F}_{c}\left(E, \theta_{d}\right)+\frac{t}{\lambda_{1}} F\left(\Theta_{d}\right) \frac{\lambda_{1}}{\lambda_{K}^{2}} \mathscr{F}_{c}\left(E, \theta_{d}\right) * g_{K}(E)
$$

where * represents the convolution product of two functions.

These relations allow to compute the energy loss spectra and to compare them to the experimental ones. The dotted curve (Fig. 2) corresponds to a computed spectrum fitted with an experimental spectrum (full curve) got with a $410 \mathrm{~nm}$ thick carbon foil at $1000 \mathrm{kV}$. The availability of the previous relations and of the models chosen to represent the energy loss functions, has been checked with various kinds of samples, thicknesses and experimental conditions: accelerating voltage and selecting slit width. In any case we reached a good fitting between experimental and computed spectra (to be published). 


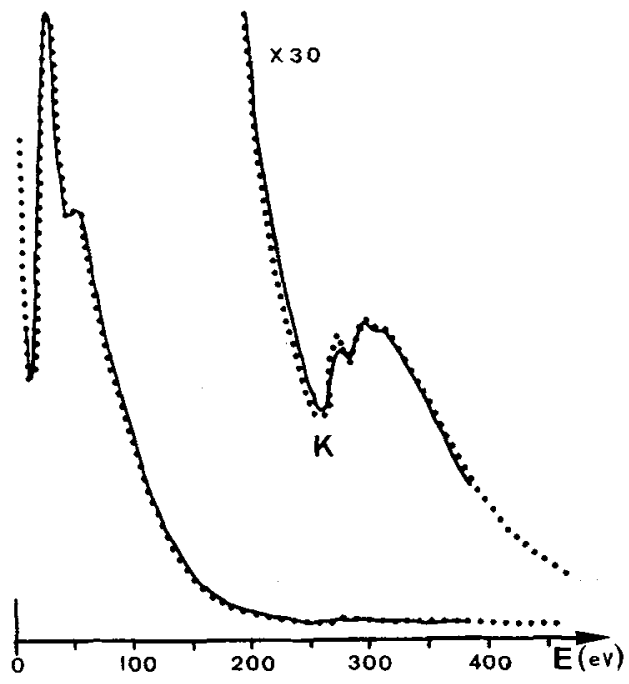

Fig. 2 : Comparison of an experimental (full curve) and calculated (dotted curve) energy loss spectrum for a $410 \mathrm{~nm}$ thick evaporated carbon film at $1000 \mathrm{kV}$.

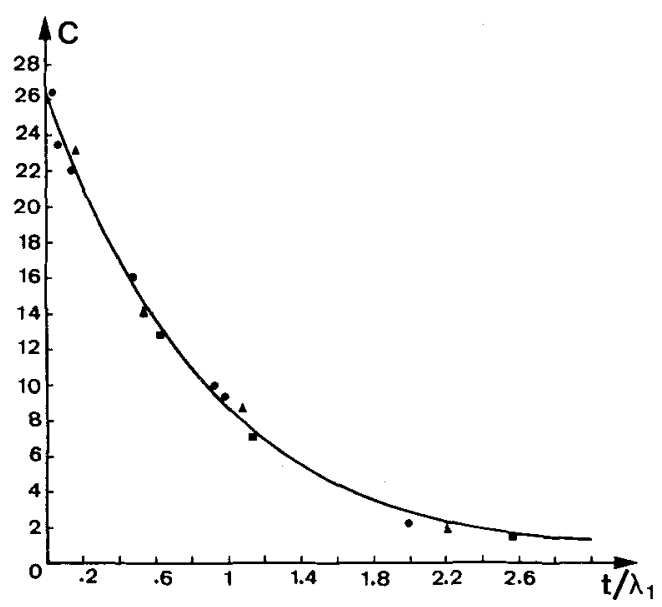

Fig. 3 : Variation of the K-ionisation edge contrast as a function of $t / \lambda_{1}$ for carbon evaporated foils. Full curve : calculated results. Points : expemental results got at $1000 \mathrm{kV}(\bullet), 500 \mathrm{kV}(\Delta)$, $300 \mathrm{kV}(:)$.

The characteristic signal contrast has been measured from the computed spectra and compared with the experimental results. The full curve of Fig. 3 represents the variation of the computed contrast values as a function of $t / \lambda_{1}$.

The points correspond to experimental values got at various accelerating voltages with carbon foils of different thicknesses. The experimental results are in good agreement with the calculated values.

The contrast of the characteristic distribution depends on the accelerating voltage through the mean free paths associated with the various inelastic scattering processes. $\lambda_{1}, \lambda_{2}$ and $\lambda_{k}$ are increasing functions of the accelerating voltage. The curves which describe this evolution have nearly the same shape, so that the ratios $\lambda_{1} / \lambda_{2}$ and $\lambda_{1} / \lambda_{K}$ remain scarcely constant and the contrast depends on the accelerating voltage only through the parameter $t / \lambda_{1}$. 


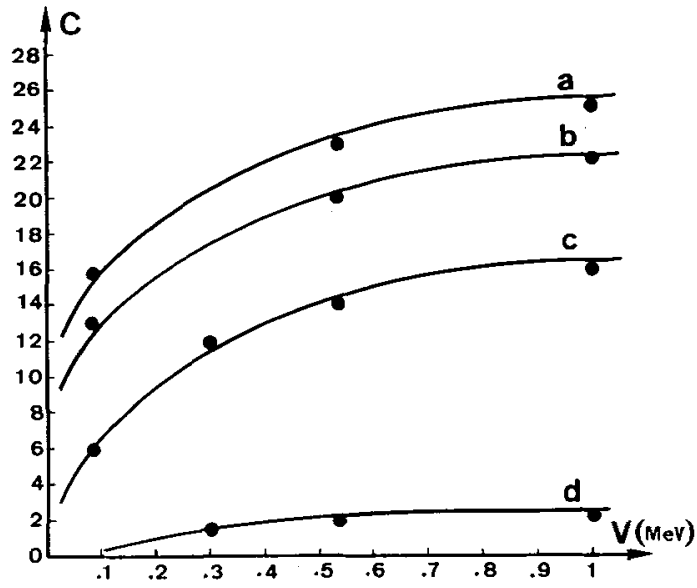

Fig. 4 : Variation of the K-ionisation contrast as a function of the accelarating voltage for various thicknesses of carbon evaporated films. (a) : $16 \mathrm{~nm}$, (b) : $32 \mathrm{~nm},(\mathrm{c})$ : $100 \mathrm{~nm}$, (d) : $410 \mathrm{~nm}$.

The conclusion may be drawn that it is better to work with high energy electrons, mainly when the specimen cannot be made thinner enough. These inferences are in good agreement with the curves of Fig. 4 which show the experimental variation of the contrast as a function of the accelerating voltage for various thickness values of the sample.

\section{CONCLUSION}

The technique of chemical microanalysis using electron energy losses is all the more sensitive as the $t / \lambda_{1}$ value is small. Consequently, the use of high accelerating voltages in this field presents two points of interest :

- For a given thickness of the specimen, the sensitivity of the method increases. That involves an extension of the range of energy losses available to identify the elements of the specimen, (usually up to $3000 \mathrm{eV}$ which is sufficient to identify any element).

- When there are difficulties in making thinner enough the specimen, for instance in the field of ceramics or geology, it may then be necessary to use high accelerating voltages. Nevertheless it does not seem to be of a great interest to go beyond 500 $k V$, as beyond this value, the mean free path of the main inelastic scattering process liable for the background remains nearly constant (6). The use of high accelerating voltage (up to $500 \mathrm{kV}$ ) allows chemical microanalysis of 200 or 300 nanometer thick specimens.

\section{REFERENCES}

(1) SEVELY J., PEREZ J.Ph., JOUfFrey B., C.R. Acad. Sc. Paris, (1973), $276,515$.

(2) ZANCHI G., SEVELY J., JOUFFREY B., J. Microsc. Spectrosc. Electronique, (1976), $2,95$.

(3) KIHN Y., PEREZ J.Ph., SEVELY J., ZANCHI G., JOUFFREY B., Proc. 6th Inter. Conf. H.V.E.M., Antwerp, (1980), 42.

(4) MAHER D.M., JOY D.C., EgERTON R.F., MOCHEL P., J. Appl. Phys., (1979), 50, 5105. - EGERTON R.F., SEVELY J., J. of Microsc., (1983), 129, RP 1.

(5) MISEL D.L., Advances in electronics and electron physics, (Academic Press, NewYork - London), (1973), 32.

(6) SEVELY J., PEREZ J.Ph., JOUfFREY B., Proc. 3rd Intern. Conf. on H.V.E.M. . Oxford, (1974), (Academic Press, London and New-York), (1974), 32. 